\title{
IMPLEMENTASI SUPPLY CHAIN MANAGEMENT PADA SISTEM PENGELOLAAN BARANG DENGAN MENGGUNAKAN FRAMEWORK CI (CODE IGNITER) (STUDI KASUS BENGKEL CAHAYA MOTOR CIKIJING)
}

\author{
Ivan Patriana ${ }^{* I}$ \\ Program Studi Sistem Informasi S1, FKOM Universitas Kuningan \\ Jl. Cut Nyak Dien No.36 A, Kel. Cijoho Kuningan 45513
}

\begin{abstract}
ABSTRAK
Cahaya Motor merupakan perusahaan yang bergerak dibidang jasa pelayanan perbaikan, penjualan suku cadang motor. Proses pencatatan layanan penjualan suku cadang, perbaikan, dan laporan masih dilakukan secara manual ke dalam buku catatan. Sehingga proses ini cukup rentan terhadap kerusakan dan kehilangan data. Oleh karena itu, perlu adanya sebuah sistem pencatatan yang lebih efektif dan efisien.

Sistem yang dibangun mendekati konsep Supply Chain Management yang mencakup proses pembelian barang, penjualan barang, layanan perbaikan motor, pengelolaan supplier, pengelolaan konsumen, retur barang, dan pengelolaan laporan. Dalam membangunan sistem ini penulis menggunakan Framework CI (Code Igniter). Sistem yang dibangun menggunakan PHP dan database menggunakan MySQL. Sistem yang dibangun dapat memberikan solusi dalam pencatatan layanan jasa, pembelian, penjualan suku cadang, serta perbaikan motor telah dilakukan secara komputerisasi dan komunikasi antara konsumen dan perusahaan menjadi lebih efektif dan efisien.
\end{abstract}

Kata kunci: Code Igniter, Supply Chain Management, Penjualan, PHP

\section{ABSTRAC}

Cahaya Motor is a company engaged in repair services, sales of motor spare parts. The process of recording sales service spare parts, repairs, and reports is still done manually into the notebook. So the process is quite vulnerable to damage and loss of data. Therefore, the need for a more effective and efficient recording system.

The system is built close to the concept of Supply Chain Management which includes the process of purchasing goods, goods sales, motor repair services, supplier management, consumer management, goods returns, and report management. In developing this system the author uses $C I$ Framework (Code Igniter). Systems built using PHP and databases using MySQL. The built system can provide solution in recording service, purchasing, spare parts sales, and motor repair have been done by computerization and communication between consumer and company become more effective and efficient.

Keywords: Code Igniter, Supply Chain Management, Sales, PHP

\section{PENDAHULUAN}

Sistem informasi merupakan suatu rangkaian dari beberapa komponen yang memiliki suatu tujuan yang sama untuk memberikan informasi yang tepat dan akurat begitu pun juga berlaku di perusahaan dalam pengelolaan data - data perusahaan, setiap pelakunya di tuntut untuk memberikan suatu informasi yang akurat untuk meningkatkan kwalitas dari suatu perusahaan tersebut. 
Sistem Informasi Manajemen Persediaan merupakan sistem informasi yang mengelola data transaksi dan persediaan barang. Dalam sistem persediaanbarang biasanya terdiri dari sistem penerimaan barang, sistem pembelian barang, dan penjualanbarang.

Manajemen persediaan barang yang kemudian berkembang menjadi manajemen rantai pasok (Supply Chain Management) adalah system terintegrasi yang mengkoordinasikan keseluruhan proses di perusahaan dalam mempersiapkan dan menyampaikan produk/jasa kepada konsumen (Ricky Martono: 2015). Proses ini mencakup perencanaan (plan), sumber input bagi proses (source), proses transformasi input menjadi output (make), transportasi, distribusi, pergudangan (deliver), system informasi dan pembayaran produk/jasa, sampai produk/jasa terebut dikonsumsi oleh konsumen, serta layanan pengembalian barang produk/jasa (return).

Mengingat pentingnya masalah persediaanbarang, perlu diadakan suatu sistem informasi berbasis komputer yang harusnya sistematis, terarah dan lengkap yang tentunya dipakai untuk membantu dalam menganalisa maupun pembuatan laporan dan juga sangat membantu dalam memperoleh informasi tentang data persediaan barang.Hal tersebut dapat dicapai dengan menerapkan konsep Supply Chain Management (SCM), dimana SCM dapat digunakan untuk mengelola aliran informasi, aliran produk, maupun aliran material antara supplier, perusahaan dan distributornya.

Bengkel Cahaya Motor Cikijing merupakan perusahaan yang bergerak dalam r. Ada beberapa permasalahan yang terjadi dabidang pembelian, penjualan sukucadang motor, dan service motolam pengelolaan barang yang ada di bengkel Cahaya Motor Cikijing, mengenai jumlah persediaan barang terkadang tidak sesuai dengan catatan yang dibuat, sering terjadinya kelebihan stok (Uppertock) ataupun kekurangan stok (lowerstock). Dalam proses penerimaan barang terkadang proses pengiriman produk yang tidak sesuai atau cacat produksi yang masih tercatat secara manual, tidak hanya itu dalam pelayanan transaksi pembelian, penjualan barang yang ada masih menggunakan pembukuan sederhana, sehingga kurang efektif dan efisiennya waktu yang digunakan serta terkadang terjadi kesalahan data-data yang diakibatkan oleh karyawan.

\subsection{IdentifikasiMasalah}

Berdasarkan latar belakang masalah di atas, maka dapat di identifikasikan permasalahan yang adayaitu:

1. Proses pencatatan pengelolaan stok barang masih manual.

2. Terjadiny akelebihan stok dan kekurangan stok pada produk - produk tertentu.

3. Terjadi kesulitan dalam pembuatan laporan stok barang dalam setiap bulannya.

4. Belum adanya system informasi untuk mengelola manajemen barang di Bengkel Cahaya Motor Cikijing.

\section{LANDASAN TEORI}

\subsection{Definisi Sistem}

Sistem adalah kumpulan-kumpulan dari komponen-komponen yang memiliki unsur keterkaitan antara satu dengan lainnya.

Menurut Jogiyanto (2005) Sistem adalah seperangkat elemen yang membentuk kumpulan atau prosedur - prosedur atau bagan-bagan pengolahan yang mencari suatu tujuan bagian atau tujuan bersama dengan mengoperasikan data dan atau barang pada waktu rujukan tertentu untuk menghasilkan informasi dan atau energi dan atau barang.

Dari dua pengertian tersebut, terdapat dua kelompok pendekatan di dalam mendefinisikan sistem, yaitu menekankan pada prosedurnya dan menekankan pada komponen atau elemennya. Dapat disimpulkan bahwa sistem adalah kumpulan dari elemenelemen atau prosedur-prosedur yang saling berhubungan dan memiliki tujuan.

\subsection{Definisi Informasi}

Menurut Jogiyanto (2005) Informasi adalah data yang telah diolah menjadi sebuah bentuk yang berarti bagi penerimanya dan bermanfaat dalam mengambil keputusan saat ini atau mendatang.

Informasi juga berarti kumpulan data yang diolah menjadi bentuk yang lebih berguna dan lebih berarti bagi yang menerimanya.

Dari pengertian tersebut dapat disimpulkan bahwa informasi adalah hasil dari 
pengolahan satu atau beberapa data yang memberikan arti dan manfaat untuk dapat diambil sebuah keputusan saat ini dan masa mendatang.

\subsection{Pengertian Sistem Informasi}

Menurut Tata Sutabri (2015) informasi merupakan komponen yang penting dalam suatu sistem. Informasi dibutuhkan bagi manajemen untuk pengambilan keputusan. Sistem Informasi dapat didefinisikan sebagai berikut:

Sistem informasi adalah suatu sistem di dalam suatu organisasi yang mempertemukan kebutuhan pengolahan transaksi harian, mendukung operasi, bersifat manajerial dan kegiatan strategi dari suatu organisasasi, dan menyediakan pihak luar tertentu dengan laporan - laporan yang diperlukan.

Jadi dapat disimpulkan bahwa sistem informasi adalah suatu alat yang membantu dalam menyediakan informasi bagi penerimanya dan untuk membantu dalam pengambilan keputusan bagi manajemen didalam operasi perusahaan seharihari dan informasi yang layak untuk pihak luar perusahaan.

\subsection{Komponen Sistem Informasi}

Jogiyanto HM dalam buku John Burch

Gary Grudnitski (hal 37 - 30) bahwa

komponen system informasi terdiri dari:

1. Komponen Input (Masukan)

Input atau masukan mewakili data yang masuk kedalam sistem informasi. Input disini termasuk metode dan media untuk menangkap data yang akan dimasukkan, yang dapat berupa dokumen-dokumen dasar.

2. Komponen Model

Komponen ini terdiri dari kombinasi prosedur, logika dan model matematik yang akan memanipulasi data input dan data yang tersimpan di basis data atau Database dengan cara yang sudah ditentukan untuk menghasilkan keluaran yang diinginkan.

3. Komponen Output (Keluaran)

Hasil dari sistem informasi adalah keluaran yang merupakan infromasi yang berkualitas dan dokumentasi yang berguna untuk semua pemakai sistem.

4. Komponen Teknologi
Teknologi digunakan untuk menerima input, menjalankan model, menyimpan dan mengakses data, menghasilkan dan mengirimkan keluaran, dan membantu pengendalian dari sistem secara keseluruhan.

5. Komponen Database (Basis Data)

Menurut para pakar di bidang nya (2004 :3) yang dikutip dalam buku Konsep Sistem Basis Data Dan Implementasinya Database adalah sekumpulan data store (Bisa dalam jumlah yang sangat besar) yang tersimpan dalam magnetic disk, optical disk, magnetic drum atau media penyimpanan sekunder lainnya. Ada juga yang menympulkan database adalah sekumpulan programprogram aplikasi umum yang bersifat "batch" yang mengeksekusi dan memproses data secara umum (seperti: pencarian, peremajaanm penambahan, dan penghapusan terhadap data).

6. Komponen Control (Pengendalian)

Banyak hal yang dapat merusak sistem informasi, seperti bencana alam, api, temperatur, air, debu, kecurangankecurangan, kegagalan-kegagalan sistem itu sendiri, ketidakefisienan, sabotase dan lain sebagainya. Beberapa pengendalian perlu dirancang dan diterapkan untuk meyakinkan bahwa hal-hal yang dapat merusak sistem dapat dicegah ataupun bila terlanjur terjadi kesalahan-kesalahan dapat langsung cepat diatasi.

Keenam komponen tersebut harus ada bersama-sama dan membentuk satu kesatuan.Setelah data diolah dan menjadi sebuah informasi maka barulah terbentuk sistem.

\subsection{Supply Chain Management}

Menurrut Ricky Martono (2015) Supply Chain Management atau SCM adalah konsep atau mekanisme untuk meningkatkan produktivitas seluruh perusahaan yang tergabung dalam rantai pasok melalui optimalisasi kualitas dan waktu. Supply Chain Management dapat didefinisikan sebagai sekumpulan aktifitas (dalam bentuk entitas/fasilitas) yang terlibat dalam proses transformasi dan distribusi barang mulai dari bahan baku paling awal dali alam sampai produk jadi pada konsumen akhir. Arsitektur dalam SCM terdiri dari distribution, sales 
department, purchasing department, manufacturing department, dan database.

Sistem harus di dukung dengan jaringan internet untuk menghubungkan semua aliran informasi.Yang diperoleh dengan menggunakan metode $S C M$ ini pada dasarnya terdiri dari aliran fisik berupa material atau produk, aliran pembayaran berupa uang atau credit, dan aliran informasi berupa kapasitas, jadwal pengiriman, order. Sistem informasi yang dibutuhkan berbasis web yang dapat menyediakan informasi secara real-time, sehingga proses pengambilan keputusan dalam $S C M$ dapat berjalan dengan baik. 5 komponen dasar $S C M$ diataranya perencanaan, sumber barang, Manufacturing, pengiriman, dan pengembalian.Dengan menerapkan sistem inventori dan distribusi ini diharapkan perusahaan dapat terus berkembang untuk menghadapi persaingan bisnisnya.

\subsection{Code Igniter}

Menurut Hakim (2010:8) CodeIgniter adalah sebuah framework PHP yang dapat membantu mempercepat developer dalam pengembangan aplikasi web berbasis PHP dibanding jika menulis semua kode program dari awal.

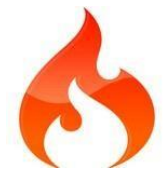

Gambar 2.2 Logo CodeIgniter

Sumber : Hakim (2010 : 9) Membangun Web Berbasis PHP dengan FrameworkCodeIgniter

CodeIgniter pertama kali dibuat oleh Rick Ellis, CEO Ellislab, Inc. (http://ellislab.com), sebuah perusahaan yang memproduksi CMS (Content Management System) yang cukup handal, yaitu

ExpressionEngine (http://www.express ionengine.com). Saat ini, CodeIgniter dikembangkan dan dimaintain oleh Expression Engine Development Team.

\section{ANALISIS DAN PERANCANGAN}

\subsection{Analisis yang SedangBerjalan}

Pada kegiatan operasional bengkel saat ini masih menggunakan catatan manual dengan menggunakan buku catatan sederhana sehingga dalam pengelolaan laporan kegiatan operasional sat ini mengalami kesulitan. Sering terjadinya out stock barang dan over stock sehinga persediaan barang kurang terkontrol, hal ini berpengaruh terhadap persediaan barang yang kurang efektif.

Analisis kegiatan operasional bengkel yang sedang berjalan ini di deskripsikan dengan menggunakan flowmap. Dimana flowmap merupakan gambaran yang menerangkan bagaimana alur data berpindah dari satu bagian ke bagian lain yang akan dijelaskan pada gambar berikut ini:

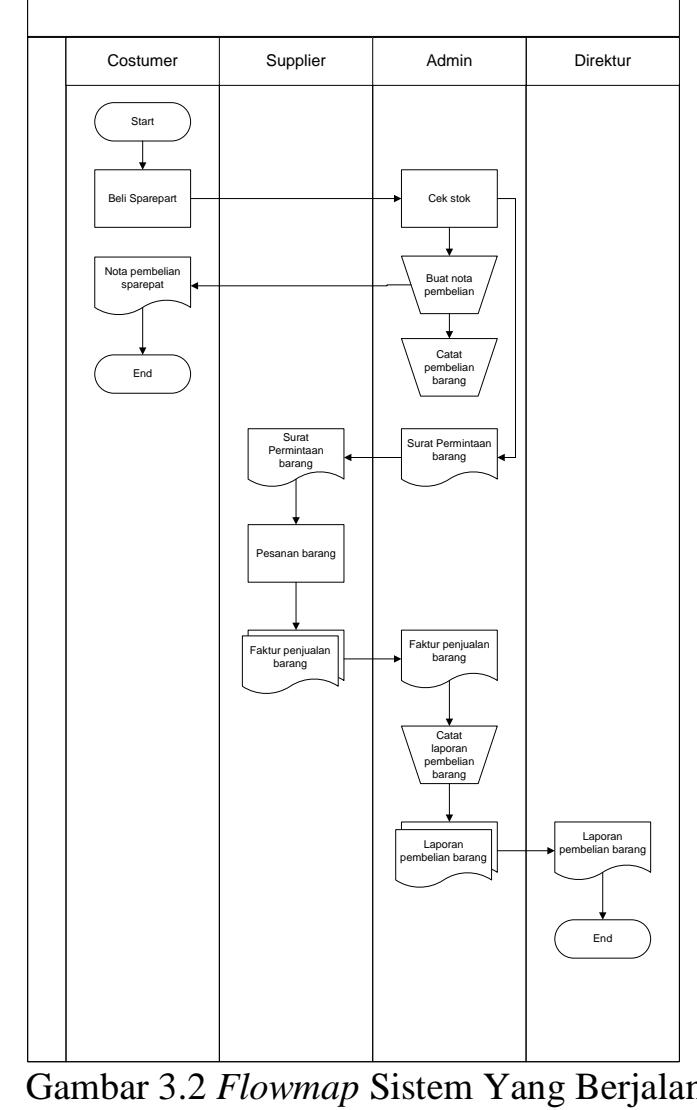

\subsection{Sistem yang Diusulkan}

Analaisis sistem yang diusulkan dalam sistem pengelolaan barang di bengkel Cahaya Motor dapat dilihat dalam gambar 3.3. berikut ini 


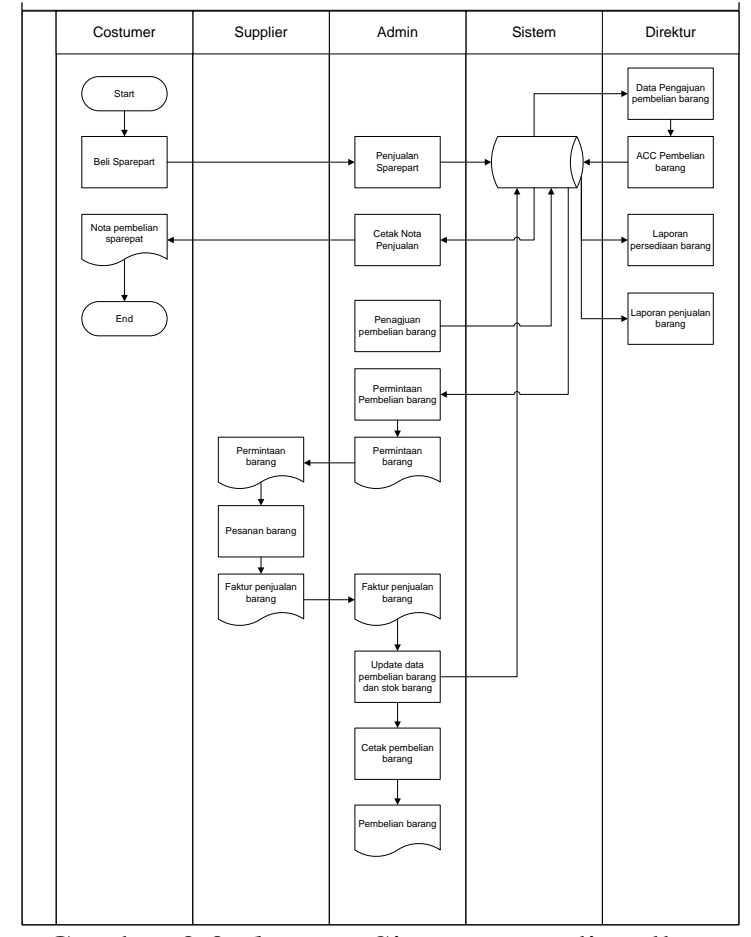

Gambar 3.3FlowmapSistem yang diusulkan

\subsection{PerancanganSistem}

1. Diagram Konyeks

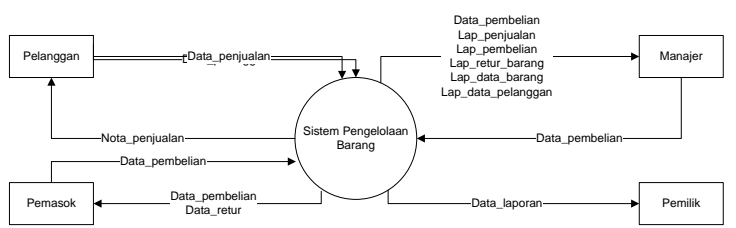

Gambar 3.4Diagram Konteks Sistem Informasi Persediaan barang

\section{Data Flow Diagram}

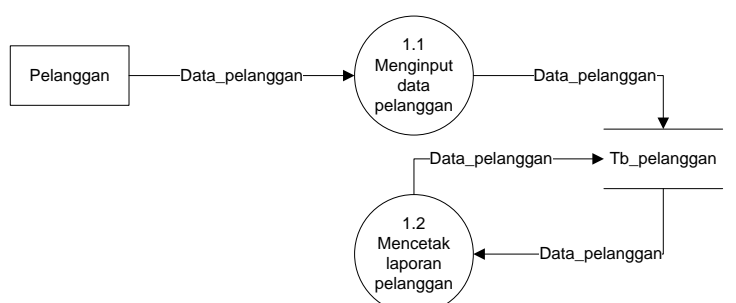

Gambar 3.5DFD Level 1

3. $E R D$

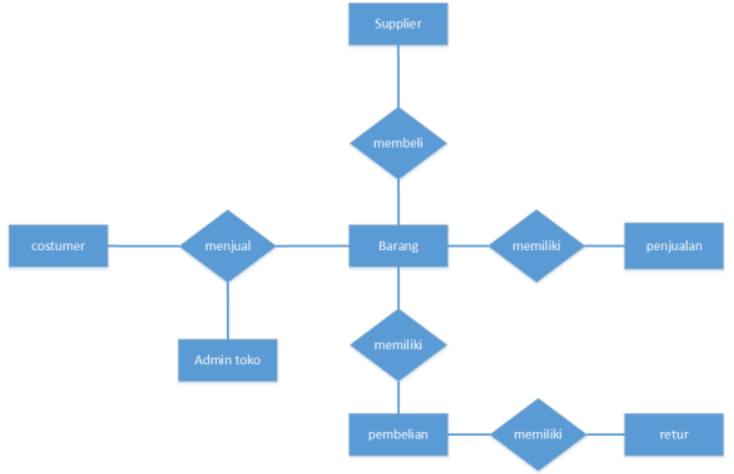

Gambar 3.8 Entity Relationship Diagram

\section{HASIL DAN PEMBAHASAN}

\subsection{Login Sistem}

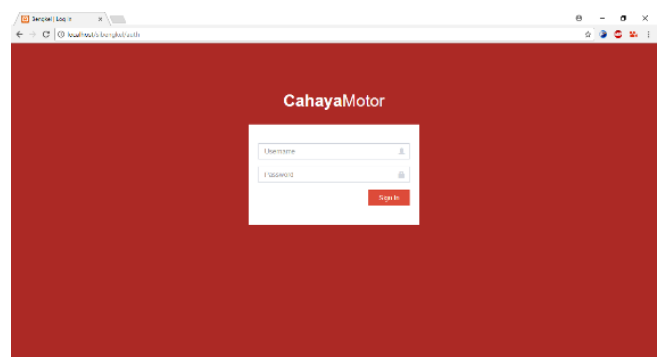

Gambar 4.1 Login Sistem

Keterangan:

1. Input Usename berfungsi untuk memasukan nama username yang sudah terdaftar pada sistem.

2. Input Password berfungsi untuk memasukan password dari akun yang sudah terdaftar.

3. Tombol Sign In berfungsi untuk masuk ke sistem ketika username dan password telah terisi

\subsection{Menu Utama}

Tampilan menu utama setelah melakukan login ke sistem

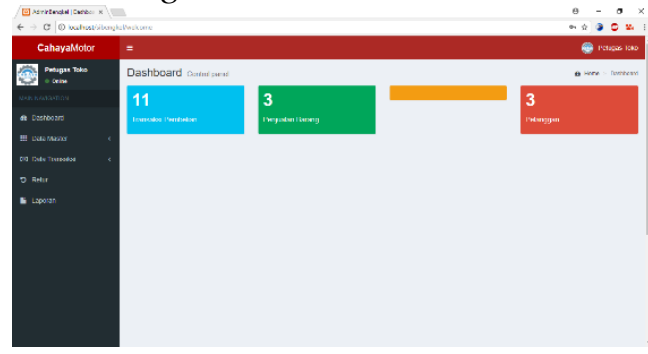

Gambar 4.2 Menu utama sistem

Keterangan: 
1. Menu Data master merupakan menu untuk mengakses data konsumen, barang dan supplier.

2. Menu Data Transaksi merupakan menu untuk mengakses transaksi pembelian barang dan penjualan barang.

3. Menu Retur merupakan menu untuk mencatat transaksi barang retur yang cacat atau bermasalah.

4. Menu Laporan merupakan menu untuk melakukan proses pembuatan laporan, baik itu penjualan, pembelian dan barang.

\subsection{Daftar Supplier}

Tampilan daftar supplier yang

sudah terdaftar di sistem

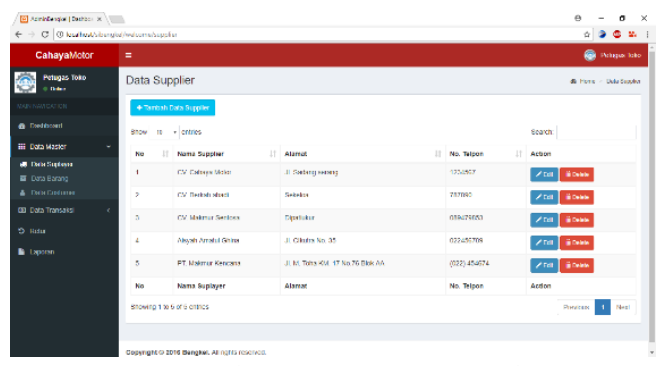

Gambar 4.3 Data Supplier

Keterangan:

1. Data supplier menampilkan semua supplier yang telah terdaftar dalam sistem.

\subsection{TampilanMenu Data Barang}

Tampilan informasi data barang yang terdaftar dalam sistem

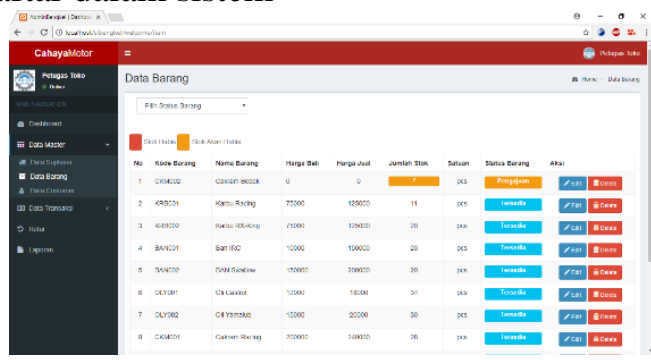

Gambar 4.5 Data Barang

Keterangan:

1. Data barang berfungsi untuk menampilkan mengenai barang yang telah tercatat dalam sistem.
2. Status barang berfungsi untuk memberikan informasi kepada pengguna mengenai ketersediaan barang.

3. Ketika stok barang $<=10$ maka sistem akan meberikan pemberitahuan dengan warna orange pada jumlah stok

4. Ketika stok barang habis maka sistem akan meberikan pemberitahuan dengan warna merah pada jumlah stok.

\section{KESIMPULAN}

Berdasarkan hasil uraian yang telah penulis lakukan berkaitan mengenai Implementasi Supply Chain Management pada Sistem Pengelolaan Barang dengan Menggunakan Framework CI (Code Igniter) (Studi Kasus Bengkel Cahaya Motor Cikijing):

1. Proses pencatatan pengelolaan persediaan barang telah dilakukan secara komputeriasi

2. Dalam pengelolaan laporan persediaan barang, jual beli barang dan retur barang lebih baik dibandingkan dengan pengelolaan laporan sebelumnya yang masih menggunakan manual

3. Terbangunnya Sistem Informasi pengelolaan persediaan barang.

4. Dengan adanya sistem informasi persediaan barang mempermudah admin dalam semua proses operasional di bengkel Cahaya Motor.

\section{SARAN}

Adapun saran penulis berdasarkan hasil rancangan dan kesimpulan yang telah penulis rangkum adalah sebagai berikut :

1. Perlu adanya pengembangan dari sistem yang telah dibuat agar lebih baik dan terperinci dalam pengelolaan barang.

2. Sistem yang telah dibuat diharapkan untuk dilakukan pengembangan selanjutnya agar lebih sempurna.

\section{DAFTAR PUSTAKA}

Anatan, Lina. Ellitan, Lena, 2008. Supply Chain ManagementTeori dan Aplikasi. CV. Alfabeta:Bandung

Ayuliana, 2009. Testing dan Implementasi.

Bowerman, B.L. and O'Connell, R.T., 1993, Time series analysis 
forcasting: An applied approach (3rded). Boston: Duxbury Press.

Boubekri, N., 2001. Technology enables for supply chain management.

Integrated Manufacturing System , 16(2), 394-399.

Hartono, Jogiyanto. 2005. Analisis \& Desain Sistem Informasi :

Pendekatan Terstruktur Teori dan Praktek Aplikasi Bisnis. Andi : Yogyakarta.

Hanke, J.E \& Wichern D.W. 2009. Business Forcasting ( $9^{\text {th }}$ edition).

New Jersey: Pearson Prentice-Hall. Inc.

Marlinda, Linda. 2004. Sistem Basis Data. Yogyakarta : ANDI.

Martono, Ricky. 2015. Manajemen Logistik Terintegrasi. PPM Manajemen: Yogyakarta

Nugroho, Adi. 2004. Konsep Pengembangan Sistem Basis Data. Informatika : Bandung.

Parno S.Kom, MMSI. (2006). Data Flow Diagram. Retrieved February,

282010 from.

Sutabri, Tata. 2015. Sistem Informasi Manajemen (Edisi Revisi). Andi: Yogyakarta

Whitten, J . Bentley, L. Dittman, K (2004). Desain dan Analisis Sisitem(6rd ed) Yogyakarta : Andi (Original Work (2004) McGrawHill). 